\title{
METHOXYFLURANE (PENTHRANE): A REPORT OF 1,200 CASES
}

\author{
F. W. McGaffrey, M.D., and Mafla J. Mate, M.d."
}

THE SEARCH for new agents in anaesthesia was greatly stimulated by the introduction of halothane by Raventos ${ }^{1}$ with its subsequent wide acceptance. Since then, other fluorinated substances have been investigated by Artusio and Van Poznak. They first reported their clinical evaluation of one of these, methoxyflurane (Penthrane), in man in 1960. ${ }^{2}$ Methoxyflurane has been in use in St. Paul's Hospital, Vancouver, since August 1961 and has been the main anaesthetic agent in a wide variety of surgical procedures performed on patients of all ages and all risks. This review will deal with our clinical experiences in over 1,200 cases.

\section{Chemical and Physical Properties}

Methoxyflurane is 2,2-dichloro-1,1-difluoro-ethyl methyl ether:<smiles>FC(Cl)C(F)(F)Cl</smiles>

It is a clear, colourless liquid with a characteristic sweet, fruity odour. It is nonflammable and non-explosive in air or oxygen in anaesthetic concentrations at room temperature. The vapour concentration is limited by the efficiency of the vaporizer to an absolute maximum of 4 per cent at $23^{\circ} \mathrm{C}$. by its vapour pressure. It is chemically stable in the presence of light, oxygen, moisture, and carbon dioxide absorbents. A yellow to brownish discolouration does occur on prolonged exposure to light, which is apparently due to an added anti-oxidant, but it has no untoward action and does not alter its efficiency in any way. We have utilized samples which had become deeply coloured without being able to detect any adverse effect.

Methoxyflurane appears to be compatible with all other agents ordinarily employed in anaesthesia.

Many more physical constants of methoxyflurane are supplied in the manufacturer's literature. ${ }^{3}$

\section{Method of Administration}

Initial information gave the impression that methoxyflurane was endowed with a combination of some of the better features of halothane and diethyl ether.

Our patients were premedicated in the usual manner according to age and physical and emotional status. Depending on the preference of the individual anaesthetist, all of the commonly used premedicating drugs were used without any unexpected effect. (The ages of the patients in this series are shown in Table

¿From the Department of Anaesthesia, St. Paul's Hospital, Vancouver, B.C., and the Faculty of Medicine, Section of Anaesthesia, University of British Columbia, Vancouver, B.C. 
I, and the physical status in Table II according to the Dripps, Eckenhoff, and Vandam modification of the ASA rating.)

While we accept that the properties of methoxyflurane are such that it can be termed a "complete anaesthetic," we do not think that application of this concept

TABLE I

Ages of Patients

\begin{tabular}{cc}
\hline \hline Age, years & $\begin{array}{l}\text { Number } \\
\text { of cases }\end{array}$ \\
\hline $0-1$ & 18 (youngest, 1 month) \\
$2-5$ & 63 \\
$6-10$ & 62 \\
$11-20$ & 74 \\
$21-30$ & 121 \\
$31-40$ & 195 \\
$41-50$ & 266 \\
$51-60$ & 187 \\
$61-70$ & 123 \\
$71-80$ & 81 \\
81 and over & 10 (oldest, 87) \\
Total & 1200 \\
\hline
\end{tabular}

TABLE II

Physical Status of Patients

\begin{tabular}{lr}
\hline Class I & 743 \\
Class II & 353 \\
Class III & 94 \\
Class IV & 10 \\
& \\
Total & 1200 \\
\hline
\end{tabular}

leads to the optimum utilization of this agent. We believe that it should be combined with other anaesthetic agents such as sodium thiopentone, nitrous oxide, and muscle relaxants when necessary, using it as the main element of a "balanced anaesthesia." Similar conclusions were reached by Kok et al. in a study of 700 cases given methoxyflurane anaesthesia. ${ }^{5}$

\section{INDUCTION}

In adults we have preferred a sodium thiopentone induction with transition to nitrous oxide, oxygen, and methoxyflurane. While the induction time is moderately slow, it is, however, very smooth. We found that ten to twenty minutes of induction of gradually increasing amounts of methoxyflurane is usually required before a stable state of anaesthesia can be achieved.

In young children, our usual procedure was to induce with nitrous oxide, oxygen, and cyclopropane, gradually decreasing the amount of cyclopropane as the methoxyflurane concentration was increased.

'There was no doubt that some respiratory depression could occur with methoxyflurane, as has been noted by other investigators, ${ }^{4,6,7}$ who have pointed out the advisability of using assisted or controlled respiration. Occasionally considerable cardiovascular depression was also seen, particularly if the agent was being "pushed." It is therefore mandatory that respiration and blood pressure be constantly observed. 


\section{Maintenance}

If airway problems were absent and marked muscle relaxation unnecessary, we simply assisted the respirations by mask as indicated. For surgery where an airway difficulty was anticipated, as well as for surgery of the head and neck, and intra-abdominal or intrathoracic procedures, endotracheal anaesthesia with controlled respirations was most frequently used. Spraying the vocal cords with 4 per cent lidocaine at intubation facilitates the smooth transition to maintenance levels.

While recognizing the muscle-relaxing properties of methoxyflurane, ${ }^{8}$ we preferred to use muscle relaxants in conjunction with it. By this method we were able to avoid deep anaesthesia and to have our patients awake or readily rousable at the end of operation. After anaesthesia was well established, low concentrations of methoxyflurane were usually sufficient for smooth maintenance, and the longer the duration of the operation, the lower the concentration of methoxyflurane that was necessary. Maintenance concentrations varied between 0.3 and 0.8 per cent.

Boyle ether vaporizers (outside of the circle system) ${ }_{2}^{4}$ Heidbrınk No. 8 vaporizers on the inspiratory side, Vernitrol vaporizers, and Pentec vaporizers were used for vaporization of methoxyflurane. The Pentec is a precision vaporizer which delivers concentrations of methoxyflurane according to a calibrated dial regardless of gas flows, in the manner that the Fluotec delivers halothane. Our rough measurements of amounts used with the Pentec vaporizer gave us the graphs depicted in Figure 1.

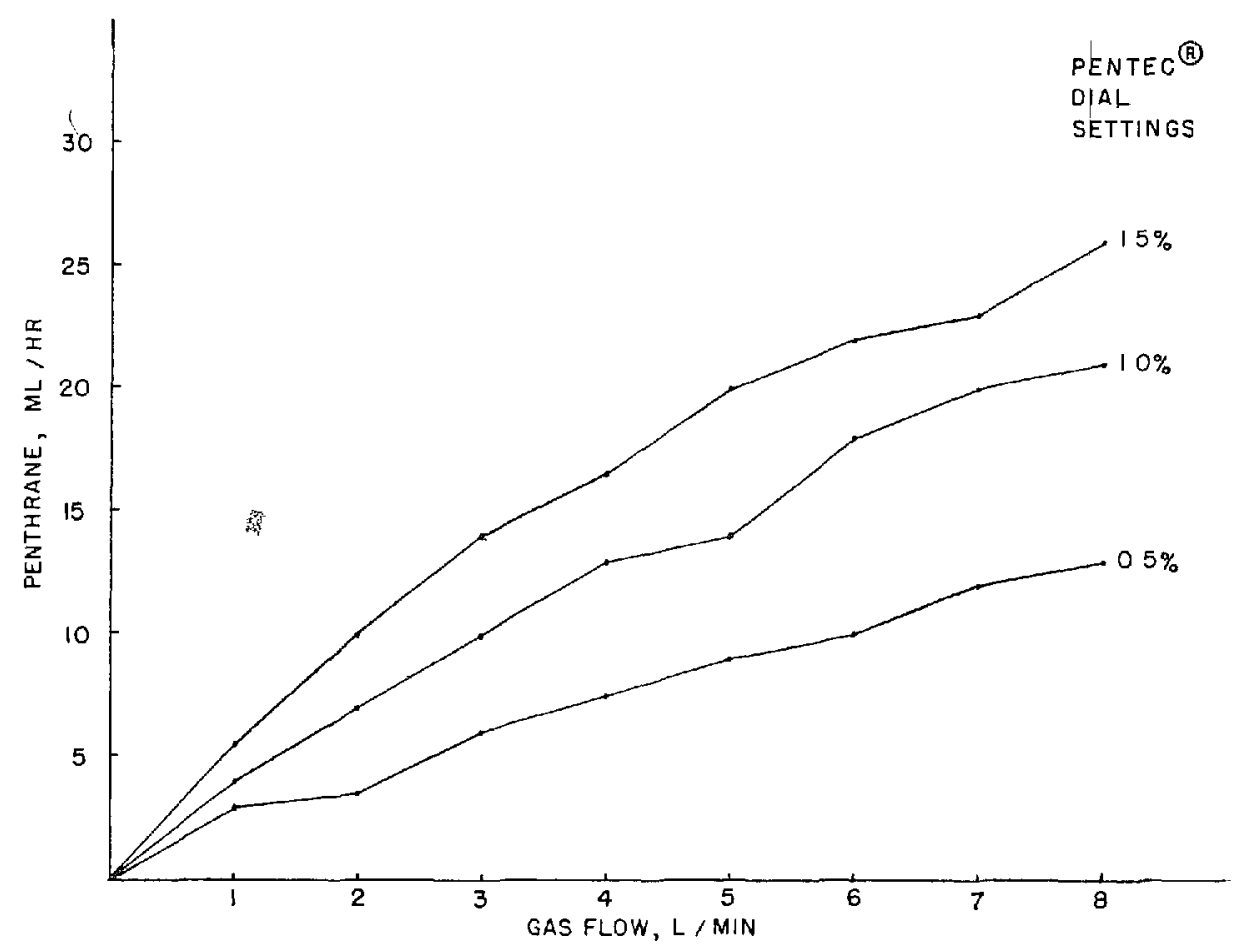

FIGURE 1

The sites of operation in our series are indicated in Table III, and the duration of these operations in Table IV. 
TABLE III

Site of Operation

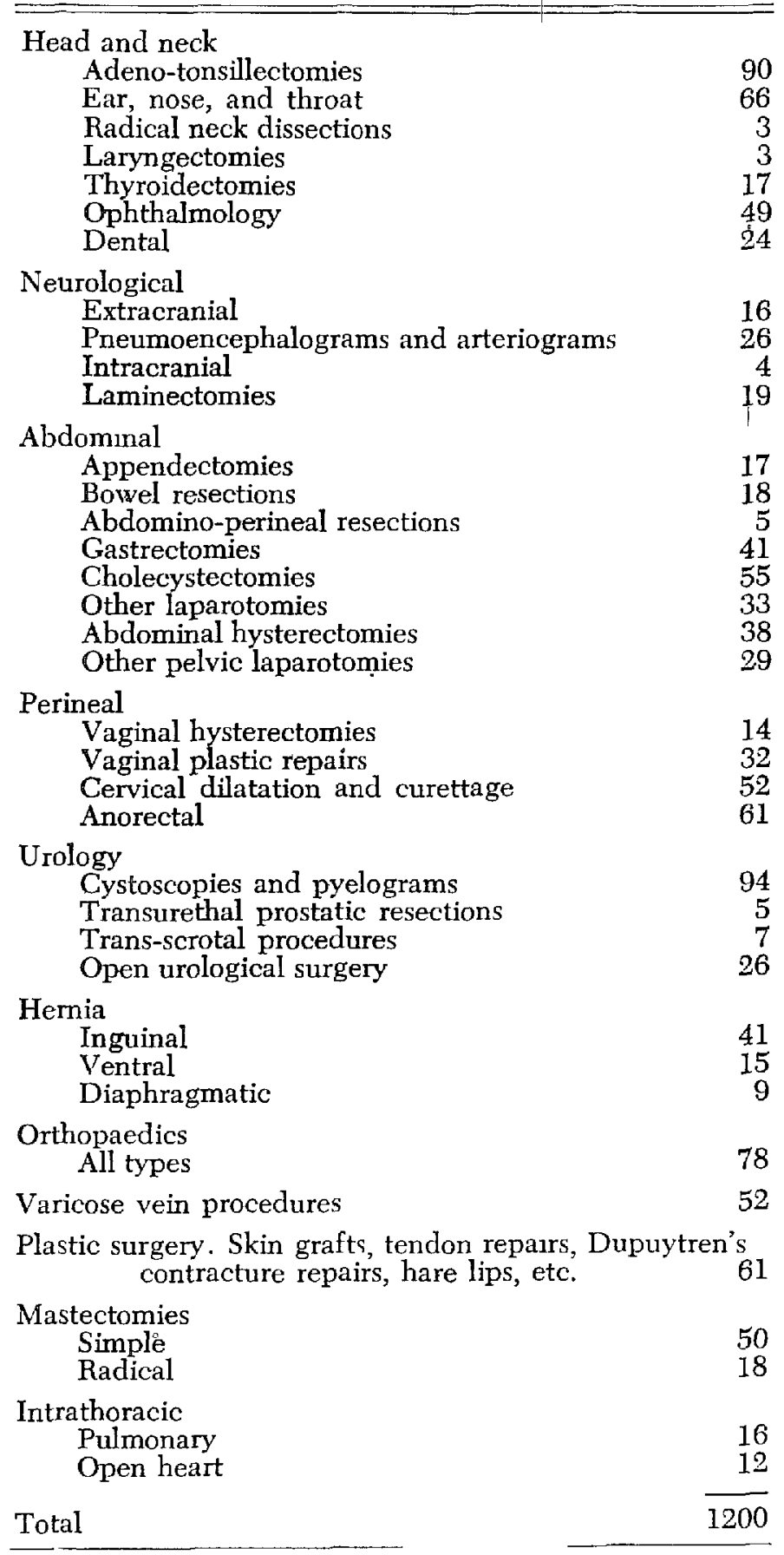

\section{EMERGENCE}

While the prolongation of emergence from methoxyflurane anaesthesia has seemed a disadvantage according to some earlier investigators, we felt that this problem became less with increasing experience with the agent. We have pointed out that using balanced anaesthesia techniques, low concentrations of methoxyflurane were sufficient, and with increasing experience in the manner in which these concentrations could be progressively decreased with longer operating time, it 
TABLE IV

Duration of Operation

\begin{tabular}{|c|c|}
\hline $\begin{array}{l}\text { Time, } \\
\text { hours }\end{array}$ & $\begin{array}{l}\text { Number } \\
\text { of cases }\end{array}$ \\
\hline 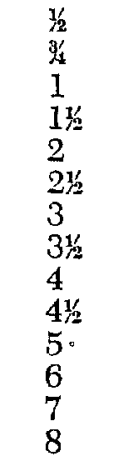 & $\begin{array}{r}115 \\
231 \\
321 \\
182 \\
158 \\
64 \\
61 \\
27 \\
24 \\
9 \\
4 \\
2 \\
1 \\
1\end{array}$ \\
\hline Total & 1200 \\
\hline
\end{tabular}

was possible to have patients reacting soon or immediately after|the termination of the operation. This was in part the reason that we preferred to use muscle relaxants in addition to the methoxyflurane, since with methoxyflurane alone, higher concentrations were required resulting in longer emergence.

The characteristics of the emergence appeared to us quite striking. We have yet to see a true excitation state develop. Patients awakened very quietly and their appreciation of pain was more gradual than the usual, as has been previously pointed out.,5,11,12 The lingering analgesic effect, even when the patients had regained consciousness, was a noteworthy feature and considerably diminished the need for postoperative narcotic-type drugs. Frequently this need was diminished by at least half in the early postoperative hours. The patients usually lay quietly, appearing to be asleep, yet readily rousable. We have noted that alcoholic patients have awakened just as quietly as the ordinary patient.

In our opinion nausea and vomiting were greatly diminished. We did not keep total count in this series, but did run separate counts on a few hundred, and would rank the quality similar to that obtained with halothane in this respect. This is in agreement with the findings of Artusio, Wasmuth, Hudon, Stephen ${ }^{2,7,8}$ and in contrast with Campbell's statement. ${ }^{15}$

Patients who were anaesthetized for long periods of time sometimes looked quite pale in the recovery room and occasionally exhibited some cyanosis of lips and nail beds. This we found rather disturbing when first noted; yet these patients' other vital signs remained very satisfactory. Wasmuth noted this early in his work with this agent. ${ }^{11,13}$

With regard to patient acceptance, we have not had a single complaint, but we believe that there would have been some if methoxyflurane had been used as an induction agent alone in adults.

\section{EFfects on the Cardiovascular System}

With gradual increase of concentration of methoxyflurane, one can expect to see an initial moderate drop in the patient's blood pressure, which will usually 
resume a level slightly lower than the normal conscious level. ${ }^{2,5,11}$ However, it must be emphasized that the blood pressure and pulse must be constantly and carefully monitored, as they are the most reliable guides to depth of anaesthesia. There is no doubt that too rapid an increase of methoxyflurane concentration or deeper levels of anaesthesia will be revealed by a corresponding fall in blood pressure. ${ }^{2,5}$ We have frequently noted a greater initial fall in blood pressure in the hypertensive patient. "Pushing" the agent under controlled or assisted respiration can produce marked pressure changes. While not so dramatic and sudden as those sometimes seen with halothane, these changes can nonetheless be quite considerable, and the necessity for careful monitoring cannot be overemphasized. 8,10

While the pulse usually remains quite stable under methoxyflurane anaesthesia bradycardia may develop when deeper levels are reached or when respiration is being controlled vigorously. The bradycardia responds easily to atropine administration, and analeptic drugs are effective against excessive falls in blood pressure, but we rarely found these necessary, as both of these effects were easily reversed by simply decreasing the methoxyflurane flow for a short while.

In those cases in which we had an electrocardiographic monitor functioning, we were unable to detect any worrisome rhythm changes, nor did we observe arrhythmias clinically in our other cases which in our opinion might be attributed to methoxyflurane. Indeed, on several occasions we saw existing arrhythmias become regular under stable anaesthesia with this agent. This effect was previously reported by Artusio. ${ }^{2}$

When satisfactory maintenance levels of methoxyflurane were reached, most patients demonstrated a remarkable cardiovascular stability with very little variation of blood pressure or pulse. Kok et al. have been very impressed with this stability. ${ }^{5}$

Earlier reports referred to an unexplained colour change occasionally noted in geriatric patients characterized by marked pallor, although all vital signs continued to be satisfactory. ${ }^{11}$ We also saw this, but did not think that age was $\mathrm{a}$ factor, as we have observed this phenomenon in patients of various ages. It was not a frequent occurrence, and we did not consider it directly related to depth of anaesthesia.

Early literature reported no damage to the blood elements and no interference with haemostasis. ${ }^{2}$ We thought that in most cases there was a decreased bloodloss independent of any blood pressure drop. Once maintenance depths were achieved with methoxyflurane, there was frequently very little capillary oozing. Many of our surgeons have commented) upon this, particularly during such operations as radical neck dissections, laryngectomies, laminectomies, and vaginal plastic repairs. While this action seemed to be variable, we did feel that it was a noticeable feature in the majority of cases and that it had actually reduced anticipated blood replacement requirements. More precise investigation of this feature is warranted. We have augmented this "decreased oozing action" by controlling the hypotension resulting from the use of high concentrations of methoxyflurane to produce a markedly bloodless field, but do not recommend this, as patients slept too long in the post-operative period and most of the time the blood 
pressure crept back up in spite of attempts to hold it down with methoxyflurane alone. It is true that part of this "decreased bleeding" picture may be due to our preferred use of mechanically controlled ventilation with more efficient carbon dioxide elimination, but we did feel that the agent itself was playing a part in this action.

\section{EfFect on the Respiratohy System}

All observers have noted the depressant effect that methoxyfluraner has on respiration and most have emphasized the necessity of appreciating this and assisting or controlling the patient's respiration when necessary. $2,6,7,8,12,15 \mathrm{We}$ are in complete agreement with these authors and we paid rigid attention to ensuring an adequate ventilation to avoid any hypoxia or respiratory acidosis. While the surgical stimulation, in light levels of anaesthesia, could be sufficient to produce adequate tidal exchange for short periods of time, we assisted or controlled respirations in the vast majority of cases.

Under controlled respiration, of course, this depressant action no longer was a disadvantage. The use of an accurate ventimeter was an invaluable aid when administering methoxyflurane. If a spontaneous respiration technique was being used, the ventimeter immediately revealed whether the anaesthesia was depressing the respiration sufficiently to produce tidal exchanges less than minimal requirements. If controlled respiration was being used, the knowledge of the tidal volume revealed by the ventimeter was a useful guide to the adjustment of a mechanical ventilator or the variations of the anaesthetist's "educated hand." The importance of maintaining adequate tidal volumes was re-emphasized by Radford ${ }^{16}$ and we used his nomogram frequently. We found that the Wright ventimeter placed in circuit just proximal to the expiratory valve was quite satisfactory and indeed frequently very instructive.

There did not appear to be any bronchial irritation from methoxyflurane. One had to force in high concentrations in light planes of anaesthesia to produce an occasional respiratory objection on the part of the patient. We have yet to see any true laryngeal spasm from this agent. There was no increased production of secretions and we found it satisfactory with pre-existing chest disease.| We also believe that methoxyflurane enhances pulmonary compliance., ${ }^{2,15}$ In particular, asthmatics have been maintained very satisfactorily with this agent. .

The undesirable clinical actions of fluorinated hydrocarbons in anaesthesia are severe hypotension, respiratory depression, and cardiac arrhythmias. The hypotensive action of methoxyflurane was either minimal or easily reversed, and its action on rhythm was not deleterious. This was demonstrated by Dobkin and Fedoruk. ${ }^{10}$ This leaves its respiratory action as its most troublesome feature, which is the action most easily controlled by the anaesthetist.

\section{Action of Ancillary Drugs}

All types and combinations of drugs familiar in surgery and anaesthesia were used in this series without any unexpected clinical change.

Millar and Morris ${ }^{17}$ have shown that "dog plasma adrenaline and noradrenaline levels were not significantly increased during anaesthesia with methoxyflurane" 
and that, again in the dog, "Increases in the total plasma .catecholamine level resulting from haemorrhage or hypercarbia during methoxyllurane anaesthesia were less than those previously measured during anaesthesia with halothane." When first using methoxyflurane, we decided not to restrict the surgeon wishing to use adrenaline and only subsequently became aware of Bamforth's work. ${ }^{18}$ Nonetheless, we continued to allow use of adrenaline in local infiltration and were not able to detect any adverse manifestations. In this series, adrenaline was used in thirty-nine cases, and we continue to allow the surgeon freedom to use it whenever he so desires. This relative clinical safety of the concomitant use of adrenaline was borne out by Hudon, ${ }^{7}$ Stephen, ${ }^{8}$ North and Knox, ${ }^{19}$ and Kok et al. ${ }^{5}$

We were not convinced that methoxyflurane magnified or lengthened the action of muscle-relaxing agents as previously stated by some investigators. We did, however, grade our dosage of relaxants more carefully and avoided excessive amounts.

Our experience with the combination of methpxyflurane and Arfonad was too limited to justify comment.

It has previously been pointed out that the size of the pupils is of little value in determining the degree of anaesthesia obtained with methoxyflurane, as the pupils were early fixed and constricted., ${ }^{25}$ This was corroborated by our experience. However, the usual eye signs of tearing, movement, and light reflexes could be observed in very light anaesthesia.

Again we draw attention to the fact that changes in respiration, blood pressure, and pulse are the cardinal signs indicating the depth of anaesthesia with this agent.

\section{Non-explosive Feature}

We felt that the non-explosive nature of the agent was most important and this was the first feature which drew our attention to methoxyflurane.,.5 The modern necessity of using non-explosive techniques with the increased use of cauteries, electrical monitoring equipment, etc., is self-evident. Hospitals which have problems of decreasing conductivity of floors, or added danger of static sparks from decreased humidity, might want to encourage the use of agents of this nature.

From Figure 1 it is easy to estimate the cost involved in using anaesthesia with methoxyflurane. It is evident that additional safety need not involve greater expense.

Throughout this lengthy clinical trial we have detected no deterioration in our anaesthesia equipment, be it rubber, plastic, or metal.

\section{Use of Methcxyflutane in Open-Heart Surgery}

We felt that there was an indication for methoxyflurane anaesthesia in openheart surgery. Its features of longer emergence, stable cardiovascular action in light levels, increased lung compliance favouring controlled ventilation, and nonexplosiveness were all welcome assets for managing anaestheșia for open-heart surgery.

The preliminary surgical phases of these operations require considerable time, allowing anaesthesia to be well stabilized. This permits a high enough tissue saturation of methoxyflurane to develop so that the "long emergence factor" is 
turned to advantage. From the time the patient is put on the punhp-oxygenator to the end of the operation, usually no anaesthesia is used other than 50 per cent nitrous oxide. Most frequently patients are awake or easily roused at the end of operation, and the need for immediate postoperative sedation is greatly delayed because of the persistent analgesic effect of methoxyflurane.

\section{SUMMARY}

Our clinical experience with the administration of over 1,200 anaesthetics using the new halogenated anaesthetıc agent methoxyflurane (Penthrane) has besen very favourable and it is a popular agent in this hospital.

The induction period is similar in length to that of ethyl ether, but always smooth because it is non-irritating.

We have made observations on induction, maintenance, and emergence, and have added our recommendation for assisted or controlled respiration in the management of anaesthesia with this agent. Monitoring of the cardiovascular response is essential to appreciate the depth of anaesthesia. We have noted stability of cardiac rhythm, with cardiac depression appearing to be a more gradual phenomenon than that seen with halothane.

A very smooth maintenance can usually be achieved, and, with added experience, the length of emergence can approach that of other agents currently used.

The non-explosive qualities are important, and we particularly feel that the use of methoxyflurane is indicated in the management of anaesthesia for open-heart surgery.

We are now using methoxyflurane in a large proportion of our cases undergoing anaesthesia, for patients of all ages and all risks, and have found no contraindications to its use.

Material for this paper was originally gathered in March 1962. Since that time, we have continued to use methoxyflurane very satisfactorily, and have now administered the agent to over three thousand cases. We have had no cause to change our original opinions.

\section{RÉSUMÉ}

Notre expérience clinique, basée sur l’administration de plus de mille deux cents anesthésies au methoxyflurane (Penthrane), un nouvel agent anesthésique halogéné, a été très favorable. Cet agent est devenu très populaire dans notre hôpital.

La période d'induction est d'une durée comparable à celle de l'éther, mais elle est toujours calme parce que l'agent n'est pas irritant.

Nous avons fait des observations sur l'anesthésie utilisant cet agent, et d'accord avec nos prédécesseurs, nous avons recommandé que la respiration soit ou assistée ou controlée pendant l'anesthésie au Penthrane. Nous voulons signaler que la surveillance de l'état cardiovasculaire est essentielle pour apprécier la profondeur de l'anesthésie. Nous avons constaté un état stable du rythme cardiaque. S'il y a dépression de l'action du cœur, le phénomène est plus graduel qu'avec l'halothane.

Un état de maintien très stable peut généralement être obtenu. Avec de l'expérience, on peut contrôler la période de réveil de manière à la rendre comparable à eelle des autres agents couremment employés. 
Son caractère non explosif est très important et nous croyons qu'il est spécialement indiqué pour les operations à cœur ouvert.

Nous utilisons le methoxyflurane (Penthrane) dans une grande proportion des anesthésies chez nos malades de tout âge et de tout risque et, en effet, nous n'y avons pas trouvé de contre-indication réelle. Nous avons maintenant administré au delà de trois millé anesthésies utilisant le Penthrane:

\section{ACKNOWLEDGMENTS}

We wish to give credit to N. McMillen, M.D., W. Esdale, M.D., J. O'Donnell, M.D., G. Robinson, ar.D., L. Meloche, M.D., P. Kenny, m.D., R. Thorp, M.D., M. Griffiths, M.D., G. Bewley, M.D., and J. Treloar, M.D., members of the Department of Anaesthesia of St. Paul's Hospital who have participated in this clinical trial.

We thank all members of the recovery room staff for their excellent immediate postoperative observations.

Our thanks and appieciation are here expressed| to our surgeons for bearing with us in our early experiences with methoxyflurane.

The authors wish to thank Abbott Laboratories of Montreal, Canada, particularly Mr. Gerard R. Tremblay, Director of Pharmaceutical Sales, and Dr. Peter H. Nash, Medical Director, for their encouragement and expert advice, and for providing the very generous amounts of methoxyflurane (Penthrane) which made this clinical trial possible.

We also wish to thank Fraser Sweatman Inc., for the use of the Pentec vaporizer.

\section{REFERENCES}

1. Rayentos, J. The Action of Fluothane-A New'Volatile Anaesthetic. Brit. J. Pharmacol. II: 394 (1956).

2. Artusio, J. F. Jr.; Van Poznak, A.; Hunt, R. E.; Tyers, F. M.; \& Alexander, M. A Clmical Evaluation of Methoryflurane in Man. Anesthesiology $2 \mathcal{I}: 512$ (1960).

3. Professional Literature Pamphlet: Penthrane (Methoxyflurane) Abbott. Published by Medical Research Department of Abbott Laboratories Ltd., Canada.

4. Power, D. J. McGill University Experiences with Methoxyflurane. Canad. Anaesth. Soc. J. 8: 488 (1961).

5. KoK, O. J. S.; De Villiers, L. S.; Cilliers, A. J ; Oosthutzen, O. A.; Kruger, P.; \& DreYer, T. N. MethoxyHlurane (Penthrane): A New Inhalation Anaesthetic. Medical Proceedings. Mediese Bydraes, Vol. 8, No. 1 (13 Jan. 1962).

6. Siebecker, K. L.; Jumes, M.; Bamforth, B. J.; \& Orth, O. S. The Respiratory Effect of Methoxyflurane on Dog and Man. Anesthesiology 33: 143 (1961).

7. Hudon, F. Methoxyflurane. Canad. Anaesth. Soc. J. 8: 544 (1961).

8. Knox, P. R.; Nonth, W. C.; \& Stepren, C. R. Methoxyflurane: A Clinical Evaluation. Anesthesiology 23: 238 (1962).

9. Lamoureux, L. F. \& Urback, K. F. Incidence and Prevention of Muscle Pain Following the Administration of Succinylcholine. Anesthesiology 21: 394 (1960).

10. Dobkin, A. B. \& Fedoruk, S. Comparison of Cardio-Vascular, Respiratory and Metabolic Effect of Methoxyflurane and Halothane in Dogs. Anesthesiology 22: 355 (1961).

11. Wasmuth, C. E.; Greig, J. H.; Homi, J.; Moraca, P.; Jsin, N. H., Bitte, E. M.; \& Hale, D. E. Methoxyflurane-A New Anesthetic Agent. Cleveland Clm, Quart. 27: 174 (1960).

12. Wyant, G. M.; Chang, C. A.; \& Rapicavoli, E. Methoxyflurane (Penthrane): A Laboratory and Clinical Study. Canad. Anaesth. Soc. J. 8: 477 (1961).

13. Orth, O. S. Fluonnated Agents. Abstracts, New York Postgraduate Assembly in Anesthesiology, Dec. 6-9, 1961.

14. Bacwell, E. E. \& Woods, E. F. Cardiovascular Effects of Methoxyflurane. Anesthesiology 23: 51 (1962).

15. Campbell, M. W.; Hvolboll, A. P., \& Brecungr, J. L. Penthrane, A Clinical Evaluation in 50 Cases. Anesth. Analg., Current Researches 41: No. 2(1962). 
16. Radford, E. P. Jr.; Ferris, B. G. Jr.; \& Kriete, B. C. Clinical Use of a Nomogram to Estimate Proper Ventilation during Artificial Respiration. New Engl. J. Med. 251: 877 (1954).

17. Mrimar, R. A. \& Morris, M. E. A Study of Methoxydlurane Anaesthesia. Canad. Anaesth. Soc. J. 8: $210(1961)$.

18. Bamforth, B. J.; Stenecker, K. L.; Kraemer, R.; \& Orth, O. S. Effect of Epinephrine on the Dog Heart during Methoxyflurane Anaesthesia. Anesthesiology 22: 169 (1961).

19. Nonth, W. C. \& Kox, P. R. The Influence of Methoxyflurane upon the Cardiovascular Response to Epinephrine. Fed. Proc. 20: 321 (1961). 